\title{
Chronic Stress-induced Acceleration of Electrophysiologic and Morphometric Biomarkers of Hippocampal Aging
}

\author{
D. Steven Kerr, ${ }^{1}$ Lee W. Campbell, ${ }^{2}$ Michael D. Applegate, ${ }^{2}$ Alvin Brodish, ${ }^{2}$ and Philip W. Landfield 2 ,a \\ Departments of 'Neurobiology/Anatomy and 'Physiology/Pharmacology, Bowman Gray School of Medicine of Wake \\ Forest University, Winston-Salem, North Carolina 27103
}

\begin{abstract}
There is increasing evidence that experimental interventions that alter adrenal corticosteroid plasma concentrations can modulate aging changes in the rodent hippocampus. However, there still is very little evidence that elevation of endogenous corticosteroid levels within physiological ranges, such as occurs during chronic stress, can accelerate hippocampal aging-like changes. In addition, almost all prior intervention studies of corticosteroid effects on brain biomarkers of aging have utilized morphologic measures of aging, and it is not yet clear whether electrophysiologic biomarkers of hippocampal aging can also be accelerated by conditions that elevate corticosteroids.
\end{abstract}

In the present studies, specific pathogen-free rats of three ages $(4,12$, and 18 months at the start) were trained for 6 months ( $4 \mathrm{hr} / \mathrm{d}, 5 \mathrm{~d} /$ week) in a two-way shuttle escape task, using low intensity foot shock. This task induces "anxiety" stress, because animals receive little actual shock, but chronic training in the task has been shown to elevate plasma corticosteroids and to downregulate hippocampal corticosteroid receptors. At the end of 6 months, animals were allowed to recover for 3 weeks and were then assessed in acute, anesthetized preparations on a battery of hippocampal neurophysiological markers known to separate young from aged animals (frequency potentiation, synaptic excitability thresholds, EPSP amplitude). The brains were then fixed and sectioned for quantification of neuronal density in field CA1 (a highly consistent anatomic marker of hippocampal aging).

The pattern of stress effects differed considerably across age groups. The two younger stress groups exhibited increased evidence of aging-like neurophysiologic change, but exhibited no indications of accelerated neuronal loss. Conversely, the oldest stress group did not show additional aging-like electrophysiologic changes (possibly because of a "floor" effect in the already-impaired aged controls), but did exhibit additional cell loss. These results suggest that electrophysiologic aging changes can be accelerated by moderate stress relatively early in life, whereas structural brain aging changes are more resistant to such stress until some other aging process develops sufficiently to act as a cofactor and increase susceptibility. Aging-dependent re-

Received June 19, 1990; revised Nov. 30, 1990; accepted Dec. 13, 1990.

This work was supported by NIH Grants AG04207, AG07767, and RR05404. We wish to thank Lisa B. Cadwallader and Dr. Andrew G. Goliszek for extremely valuable technical contributions.

${ }^{a}$ Correspondence should be addressed to Dr. P. W. Landfield, now at Department of Pharmacology, MS-305 University of Kentucky Medical Center, Lexington, KY 40536-0084.

Copyright (c) 1991 Society for Neuroscience 0270-6474/91/111316-09\$03.00/0 sistance of hippocampal corticosteroid receptors to downregulation by stress has been reported, as have alterations in calcium homeostasis. These or other molecular/cellular aging changes could act as cofactors to increase the susceptibility of aged individuals to stress-induced brain cell degeneration.

There is increasing evidence that chronic exposure to adrenal corticosteroids (CORT) plays a role in the brain aging process and contributes to the development of neuronal loss and glial reactivity in the hippocampus of aging rats. This evidence includes findings that (1) plasma CORT or adrenal weight correlate positively with measures of hippocampal aging (astrocyte hypertrophy) in rats (Landfield et al., 1978b); (2) long-term adrenalectomy ( 9 months) in aging rats protects against the development of several age-correlated hippocampal morphological changes (Landfield et al., 1981a; Landfield, 1987a); and (3) 3 months of high CORT administration to younger rats results in decreased hippocampal neuronal density (Sapolsky et al., 1985). Further, psychoactive cannabinoids, which are similar in molecular structure to CORT and interact with brain glucocorticoid receptors (Eldridge and Landfield, 1990), also induce aging-like hippocampal neuronal loss (Landfield et al., 1988). These and other data have led to a glucocorticoid hypothesis of brain aging and neurodegeneration (cf. Landfield, 1978, 1987a; Landfield et al., 1978b, 1981a; McEwen et al., 1986; Sapolsky et al., 1986).

However, there still are only a handful of studies on whether physiological elevations of endogenous CORT (e.g., with moderate chronic stress) can induce acceleration of brain aging-like changes. Several months of chronic stress can accelerate aginglike retinal degeneration in aging rats (O'Steen and Brodish, 1985; O'Steen et al., 1987). In addition, chronic shock-exercise stress can alter some aging-like changes at the neuromuscular junction (Rosenheimer, 1985). With regard specifically to hippocampal changes, one study has reported that several weeks of handling neonatal rats reduces glucocorticoid secretion in adult or aged rats in response to acute stress, and that this handling is also correlated with reduced pyramidal cell loss as the animal ages (Meaney et al., 1988). In captive monkeys found dead from undefined disease, there is also some evidence of a link between indirect measures of the amount of stress to which animals had been subjected (ulcers) and the amount of hippocampal pathology (Uno et al., 1989). In the monkeys, however, brain tissues were studied after various postmortem intervals, and the possible contributions of disease could not be excluded.

Thus, in aging-marker studies specifically of the hippocampus, there have been no long-term studies in which chronic stress was administered directly under systematic and controlled con- 
ditions. However, the possibility that stress-induced long-term elevations of endogenous corticosteroid levels might accelerate or induce brain aging-like neuropathology seems to have considerable implications for basic mechanisms of brain aging as well as for human health. Therefore, it appears important to conduct a systematic test of this hypothesis.

In addition, almost all studies of glucocorticoids/stress and brain aging have focused primarily on anatomical markers. Although several studies have found that stress for $1 \mathrm{~d}$ to several weeks can alter aspects of hippocampal electrophysiology (Foy et al., 1987; Shors et al., 1989), there have been essentially no analyses of the effects of prolonged chronic stress or glucocorticoid elevations on electrophysiologic markers of hippocampal aging.

If stress-induced elevation and endogenous CORT can accelerate brain aging processes, as hypothesized, it would be predicted that moderate and well-defined chronic stress in rats should increase both morphologic and electrophysiologic markers of hippocampal aging. A moderate, defined psychological stress, maintained over a prolonged period, appears to be one of the only available procedures for inducing sustained elevations of endogenous CORT without inducing physical trauma or damage. Consequently, to test this prediction in the present studies, we utilized a moderate, non-physically-damaging method of inducing and maintaining chronic stress over a period of 6 months (a duration that appears necessary in rats to detect subtle changes in gradual aging processes; cf. Landfield, 1987a, 1988).

It is also clearly possible that the effects of such stress might differ considerably as a function of age, because similar stress paradigms were found to induce different effects on hippocampal corticosteroid receptors depending upon age of the stressed animals (Eldridge et al., 1989). Further, the effects of stress on endocrine parameters (Simpkins et al., 1978; Odio and Brodish, 1989) and on retinal changes (O'Steen et al., 1987) have also been found to vary with age.

Although a number of electrophysiological correlates of neural aging have been reported (cf. Landfield ct al., 1978a, 1986; Barnes, 1979; Barnes and McNaughton, 1980; Rose et al., 1986; Kelly and Robbins, 1987; Bickford-Wimer et al., 1988; Smith, $1988 \mathrm{a}, \mathrm{b})$, the feasibility of using electrophysiologic measures as biomarkers of neural aging depends importantly on how simply and consistently these markers can be obtained (cf. discussion in Landfield, 1988; see also discussions on biomarkers in Baker and Sprott, 1988; Ingram, 1988; Smith, 1988b). That is, effective biomarkers of brain aging should exhibit low variability and should be compatible with measurements in relatively large groups of animals, because gradual aging processes generally induce subtle quantitative rather than extreme qualitative changes and require careful statistical analysis for detection. In addition, use of multiple biomarkers provides added reliability. However, meeting these criteria can be difficult for electrophysiologic indices, because such measurements are often time consuming, demanding, and variable.

In the present studies, therefore, we utilized a series of extracellular indices of hippocampal neurophysiology that have been found consistently to separate young from aged rats. Among the electrophysiologic markers used was frequency potentiation [FP; the short-term growth of synaptically mediated responses during trains of repetitive (e.g., 3-15 Hz) synaptic activation; cf. Andersen and Lomo, 1967], which is impaired consistently in aged hippocampus (Landfield et al., 1978a, 1986; Applegate and
Landfield, 1988). Hippocampal FP appears analogous to frequency facilitation in peripheral synapses, which depends on presynaptic mobilization of transmitter (Martin, 1977). Also, in the hippocampus FP is localized at the synapse and appears to reflect transmitter mobilization (Pitler and Landfield, 1987; Applcgatc and Landficld, 1988). Unlike long-term potentiation (LTP; cf. reviews in Landfield and Deadwyler, 1988), FP dissipates within seconds to minutes following termination of the stimulus train. LTP is changed less consistently than FP with aging, though age changes in LTP duration, rather than magnitude, have been noted (Barnes, 1979). In addition to impaired FP, reduced thresholds for eliciting EPSPs or action potentials and reduced amplitudes of field EPSPs occur consistently in the aged rat hippocampal formation (Barnes and McNaughton, 1980; Landfield et al., 1986).

These three consistent electrophysiologic markers (FP, thresholds, EPSP amplitude) were used in conjunction with a highly reliable morphologic correlate of hippocampal aging (decreased neuronal density in field CA1; cf. Landfield et al., 1981a,b; Coleman and Flood, 1987) to test the specific prediction that prolonged and well-defined chronic "anxiety" stress (6 months), for which the degrecs of CORT clcvation and brain CORT receptor downregulation have been characterized, can alter the development of both electrophysiologic and anatomic markers of brain aging.

\section{Materials and Methods}

At the start of training, the numbers of animals in each group were 22 young, 20 midaged, and 20 aged (4-, 12-, and 18-month-old, respectively) male F344 rats, obtained from the National Institute on Aging's specific pathogen-free colony. Half of each age group were trained for approximately 6 months ( $4 \mathrm{hr} / \mathrm{d}, 5 \mathrm{~d} /$ week) in a buzzer-signaled twoway shuttle escape apparatus in which mild electric foot shocks were alternated between halves of the grid floor at random variable intervals (interstimulus interval, mean $\pm \mathrm{SD}, 105 \pm 55 \mathrm{sec}$; range, $15 \mathrm{sec}$ to 5 min) during each 4 -hr session. The foot-shock intensity used was just above the minimum level required to motivate the animals to escape consistently $(0.75 \mathrm{~mA})$. An auditory signal of 2,0 -sec duration was used to cue animals just prior to each current alternation, which occurred $1.0 \mathrm{sec}$ after tone offset. There appeared to be no age differences in escape performance, and after 1 week, essentially all animals of all groups escaped within $0.5-1.0 \mathrm{sec}$ after shock onset. Therefore, almost all of each training session was occupied by interstimulus intervals in which the animals remained tense and frozen, and most of the presumed stress resulted from apparent "anxiety" rather than from shock. Use of these procedures and apparatus has been shown to elevate plasma corticosterone from resting values in the $10-20 \mathrm{ng} / \mathrm{ml}$ range to the 300 $400 \mathrm{ng} / \mathrm{ml}$ range after $1 \mathrm{hr}$ in the apparatus, and to maintain levels above $200 \mathrm{ng} / \mathrm{ml}$ for $4 \mathrm{hr}$. After almost 3 months of daily training, 1-hr values had adapted to the $100 \mathrm{ng} / \mathrm{ml}$ range in young animals $(6$ months old), but remained in the $200 \mathrm{ng} / \mathrm{ml}$ range for aged rats (22 months old; Odio and Brodish, 1989). The apparatus and procedures have been described in greater detail elsewhere (O'Steen et al., 1987; Eldridge et al., 1989; Odio and Brodish, 1989).

The other half of the young, midaged, and aged animals from the same age cohorts were maintained concurrently as home-cage controls for the duration of the 6-month training period. All animals were housed in air-barrier and filter-protected cages and were allowed food and water ad lib. The training apparatus was in an adjacent sealed room so that animals were not exposed to pathogens during transfer from home cages, and research personnel did not enter any other animal facility prior to entering this one.

None of the animals in any age group exhibited indications of physical deterioration, and no lesions or abrasions of any kind were seen. Aged stressed animals did not die at a higher rate than aged controls, and all of the stressed animals were well groomed. Moderately lower body weights were seen in each of the stressed groups in comparison to controls. However, this presumably reflected the effects of elevated plasma CORT on appetite, because in rats decreased food intake and body 


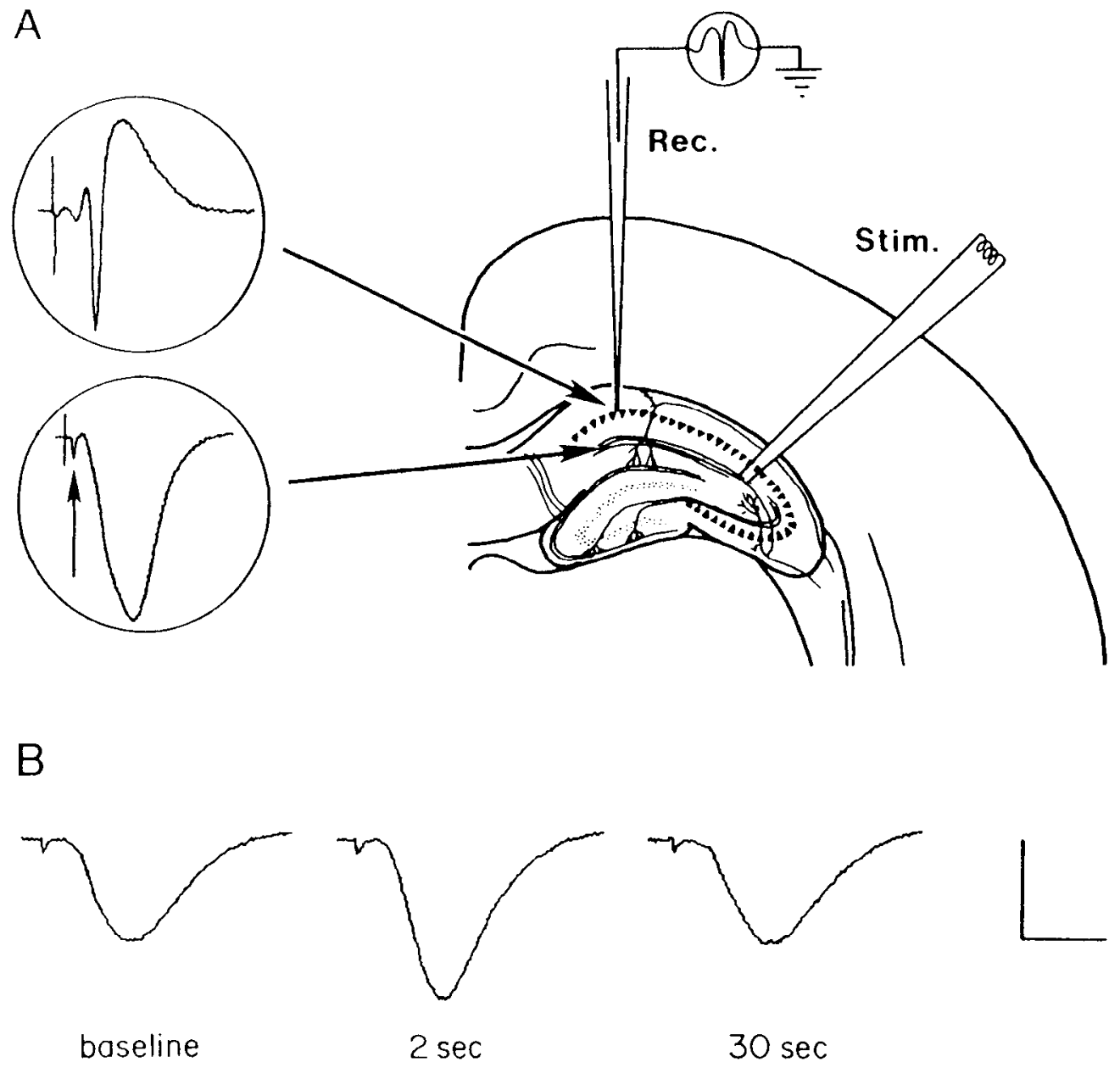

Figure 1. A, Schematic diagram of a transverse section of the dorsal hippocampal formation and approximate electrode placements used in this study. Stimulating electrodes (Stim.) were localized in the Schaffer collateral/commissural fibers (stratum radiatum) of the dorsal hippocampus; recording electrodes (Rec.) were positioned in the C.A 1 somal layer (stratum pyramidale) and, subsequently, in the CAl apical dendrites (stratum radiatum) at the point of maximum Schaffer collateral commissural synaptic density. Insets show typical evoked potentials (population spike and field EPSP) recorded at these levels within the CA1 field. Waveforms shown are the digitized average of tive individual waveforms acquired at $0.2 \mathrm{~Hz}$, at the minimum stimulation intensity necessary to elicit a maximal field EPSP. The arrow in lower inset indicates Schaffer collateral/commissural fiber spike (see Materials and Methods). B, FP of the field EPSP. Waveforms shown are from a nonstressed young animal immediately before (baseline) and during a 45-sec train of pulses elicited at $10 \mathrm{~Hz}$, at $150 \%$ of field EPSP threshold. FP is typically maximal by $2-3 \mathrm{sec}$ and usually returns to baseline amplitudes by $30-45 \mathrm{sec}$ of stimulation. Calibration, $4 \mathrm{mV}, 10$ msec.

baseline

weight is a standard response to exogenous corticosterone administration (Stevenson and Franklin, 1970; Simpson et al., 1974; Landfield, 1987a). Animals in this paradigm and those administered exogenous CORT reduce food and water intake for an initial period of several weeks, but thereafter exhibit relatively normal intake. Body weights (mean \pm SEM, in $\mathrm{gm}$ ) for all groups at the end of the experiment were as follows: young controls, $455 \pm 46$; young stressed, $418 \pm 21, p<$ 0.03 ; midaged controls, $463 \pm 25$; midaged stressed, $426 \pm 26, p<$ 0.02 ; aged controls, $430 \pm 35$; aged stressed, $412 \pm 9$, NS.

In order to reduce contributions to the physiological measures from acute stress effects, training was discontinued 3 weeks prior to the electrophysiological studies. It has been shown that stress-induced downregulation of CORT receptors recovers 3 weeks after the cessation of stress training (Eldridge et al., 1989). At the time of death, the animals were approximately 11-12 (young), 19-20 (midaged), and 25-26 (aged) months of age. Because only two or three animals could be studied electrophysiologically in any $1 \mathrm{~d}$, the cessation of training was staggered, and animals were killed over a period of approximately $45 \mathrm{~d}$. Control and stressed animals, and animals of each age, were studied alternately.

Acute extracellular microelectrode procedures similar to those described previously (Andersen, 1975; Landfield et al., 1978a; Applegate and Landfield, 1988) were employed to assess neurophysiological indices of hippocampal function in vivo. Under full urethane anesthesia (1.2 gm/5 cc saline $/ \mathrm{kg}$ ), bipolar stimulation electrodes, consisting of $0.076-\mathrm{mm}$-diameter Teflon-coated stainless-steel wire, were lowered stereotaxically into the Schaffer collateral/commissural pathway (stratum radiatum; cf. Swanson et al., 1978) of field CA3, at a point 2000 $2500 \mu \mathrm{m}$ from the anterior pole of the hippocampus (confirmed histologically following each study). In addition, physiological monitoring during electrode lowering was used for accurate placements (cf. below). Insulated tungsten recording microelectrodes (0.75-1.5 $\mathrm{M} \Omega$ impedance) were lowered initially into the stratum pyramidale of $\mathrm{CAl}$ and were used to monitor evoked responses from the stimulation electrode as it was lowered into the stratum radiatum (see Fig. 1). Stereotaxic coordinates for both electrodes were as follows: stimulation, $3.5 \mathrm{~mm}$ posterior to bregma and $3.5 \mathrm{~mm}$ lateral to the midline of the calvarium, inserted at an angle of $23^{\circ}$ away from the sagittal plane of the animal's head; recording, $3.5 \mathrm{~mm}$ posterior to bregma and $2.0 \mathrm{~mm}$ lateral to midline, at an angle of $0^{\circ}$ relative to the sagittal plane.

The extracellular monosynaptic evoked response in stratum radiatum of CA1 to Schaffer stimulation consists of a negative-going slow wave (field EPSP). In stratum pyramidale, the slow wave is positive-going because of the source-sink relationship (cf. Humphrey, 1968; Andersen, 1975 ) and, above a threshold, is associated with a sharp negative spike (population spike), which represents summation of individual neuronal action potentials (cf. Fig. 1; Andersen, 1975). In addition, a fiber spike (afferent fiber volley) can often be recorded in stratum radiatum just prior to the onset of the field EPSP (Fig. 1, arrow). This reflects the extracellular compound action potential of the Schaffer-commissural fibers and provides a measure of the degree of afferent input (Andersen, 1975; Barnes and McNaughton, 1980).

After this typical Schaffer-commissural response (Fig. 1; Andersen and Lomo, 1967; Andersen, 1975; Landfield et al., 1978a) was obtained, indicating correct electrode tip localizations, a set protocol of electrophysiological studies was performed. This protocol consisted of (1) determination of threshold and asymptotic maximal amplitude for the population spike, recorded in stratum pyramidale, in response to afferent activation; (2) lowering the recording electrode tip from stratum pyramidale into stratum radiatum, to the point that maximized the negative field EPSP (usually about the midpoint of stratum radiatum; of. Andersen, 1975; Swanson et al., 1978), and determination of field EPSP threshold; (3) determination of asymptotic field EPSP amplitude as well as, where possible, amplitude of the associated Schaffer/commissural fiber volley (fiber spike); and (4) assessment of frequency potentiation 
Table 1. Maximum amplitudes of hippocampal population spikes and EPSPs

\begin{tabular}{llccc} 
& & Young & Midaged & Aged \\
\hline Population spike & Control & $11.9 \pm 0.5$ & $12.0 \pm 0.7$ & $12.9 \pm 0.6$ \\
& Stressed & $12.7 \pm 0.8$ & $11.6 \pm 0.9$ & $10.9 \pm 0.8$ \\
Field EPSP & Control & $10.6 \pm 0.4$ & $10.0 \pm 0.5$ & $9.0 \pm 0.8$ \\
& Stressed & $9.4 \pm 0.7$ & $9.6 \pm 0.5$ & $8.3 \pm 1.0$ \\
Fiber spike at maximum EPSP & Control & $0.68 \pm 0.12$ & $0.72 \pm 0.12$ & $0.68 \pm 0.10$ \\
& Stressed & $0.53 \pm 0.08$ & $0.41 \pm 0.05^{*}$ & $0.57 \pm 0.06$ \\
\hline
\end{tabular}

Mean \pm SEM $(\mathrm{mV})$ of asymptotic responses for the population spike in stratum pyramidale and the field EPSP in stratum radiatum. The fiber spike values are for amplitudes obtained in stratum radiatum at the lowest stimulation intensity needed to induce a maximum field EPSP amplitude. The asterisk identifies the only stress group different from its same age, unstressed control group.

of the field EPSP during $45 \mathrm{sec}$ of $10-\mathrm{Hz}$ synaptic stimulation at $150 \%$ of EPSP threshold. Repeated measures were taken at 2-3 sec (maximal FP) and at $10,20,30$, and 45 sec after onset of the $10-\mathrm{Hz}$ train. Threshold was defined as the stimulus intensity (in $\mu \mathrm{A}$ ) required to produce a 0.5 $\mathrm{mV}$ response, for either the population spike or the field EPSP. A detailed input/output curve was not conducted for the EPSP and population spike because fiber spikes could not be measured consistently at lower stimulation intensities. Because of threshold differences, the absence of the fiber spike made it difficult to equate degree of afferent activation.

Signals were acquired and averaged on line (five pulses for each point in the paradigm) using a computer-based system and were subsequently analyzed off line using a waveform analysis program developed in this laboratory. Population spike amplitude was defined as the difference in millivolts between the first negative-going point of inflection along the rising slope of the positive wave and the point of maximum negativity of the population spike. Fiber spikes and field EPSPs were measured as the difference in millivolts between the baseline potential $5-10 \mathrm{msec}$ prior to the stimulation pulse (stimulus artifact) and the peak of negativity attained by cach potential (sce Fig. $1 A$, insets). On measures of maximum field EPSP amplitude (Table 1), small reversed (positive) population spikes could sometimes be seen riding on the EPSP, but these occurred after slow wave asymptote and did not interfere with amplitude measures.

Immediately following completion of the electrophysiological studies, each animal was perfused intracardially with a mixed aldehyde solution ( $2 \%$ glutaraldehyde, $2 \%$ paraformaldehyde, $0.15 \mathrm{M} \mathrm{Na}$ cacodylate buffer, $1 \mathrm{mM} \mathrm{CaCl}{ }_{2}$ ), and the brain was dissected and processed for light microscopic analysis. Specimens were blocked and trimmed to include that area of field CA1 in which aging changes have been seen consistently (Landfield et al., 1981a). The blocks were then osmicated, dehydrated, and embedded in araldite. One-micron-thick semithin sections were subsequently cut on an LKB ultramicrotome and stained with toluidine blue. CA1 nucleoli were counted blind (on coded slides), and the data were expressed as number of nucleoli per $100 \mu \mathrm{m}$ of stratum pyramidale length; only neurons within the pyramidal cell layer were counted. Previous studies have found that hippocampal pyramidal cell nucleolar diameter does not change with aging or with adrenalectomy (Landfield et al., 1981a,b), and therefore split-cell correction factors (e.g., Konigsmark, 1970) were not applied to the present anatomical analyses. These methods are described elsewhere in further detail (Landfield et al., 1981a,b, 1988).

Group differences were assessed by analyses of variance (ANOVAs) for determination of main effects of age; split-plot designs for repeated measures (during the stimulation train) were employed in the analysis of frequency potentiation data. Individual group contrasts were assessed with Bonferroni post hoc tests. Because the effects of similar stress paradigms have been found to vary substantially in different age groups in studies of retinal degeneration (O'Steen et al., 1987), hippocampal corticosteroid receptors (Eldridge et al., 1989), and neuroendocrine parameters (Odio and Brodish, 1989), the effects of stress were examined separately for each age group, using ANOVAs for repeated measures in the assessment of frequency potentiation, and two-tailed $t$ tests on the single measurement variables (e.g., threshold, amplitude, neuronal density). A probability level of $p \leq 0.05$ was used to determine statistical significance. During the course of the study, some animals were lost to age-related attrition or because of failure to achieve accurate placement of the electrodes. The final numbers of animals for each group were as follows: nonstressed, young $=11$, midaged $=9$, aged $=10$; stressed, young $=11$, midaged $=7$, aged $=8$.

\section{Results}

\section{Effects of aging}

Consistent with previous reports, these studies found a main effect of age for several hippocampal neurophysiological variables. Thresholds (stimulation intensity, $\mu \mathrm{A}$, mean $\pm \mathrm{SEM}$ ) for the population spike were significantly reduced with age (Fig. $2 A$; young controls, $884 \pm 107$; midagcd controls, $767 \pm 88$; aged controls, $486 \pm 47 ; F=6.38 ; p=0.005$ ). Similar effects were observed for field EPSP thresholds (Fig. $2 B$; young controls, $185 \pm 19$; midaged controls, $177 \pm 19$; aged controls, 125 $\pm 7 ; F=4.68 ; p=0.018$ ).

Fiber spikes could not be detected reliably at lower stimulation intensities, and the threshold differences also confounded measures of afferent activation across groups. Because fiber spike indicants of actual degree of afferent fiber activation would be needed to determine whether threshold differences affected the responses at different intensities, a detailed input/output analysis was not performed. However, the asymptotic maximum amplitude of the population spike and of the field EPSP could be assessed (Table 1). At these intensities, fiber spikes could also be observed in stratum radiatum for most animals and were measured at the lowest stimulation intensity at which the maximum EPSP was attained.

Although significant age-related reductions in maximum field EPSP amplitude have been observed in other studies, the age effect on asymptotic EPSP was not quite significant in this study $(\mathrm{mV}$, mean $\pm \mathrm{SEM}$; young controls, $10.6 \pm 0.4$; midaged controls, $10.0 \pm 0.5$; aged controls, $9.0 \pm 0.8 ; F=2.01 ; p=0.15$ ). In addition, the associated fiber spikes at maximum EPSP did not differ with age (Table 1). Maximum population spike amplitude also did not differ with age (Table 1).

ANOVA for repeated measures showed a highly significant aging-related decrease in monosynaptic FP of the field EPSP during a $45-\sec$ train $(F=5.08 ; p=0.01$; Fig. 3). As can be seen in Figure 3 , the midaged controls differed from young controls primarily in the later phases of FP, rather than in maximal FP (3-sec point), whereas the aged controls exhibited impaired FP at all points.

Light microscopic analyses of hippocampal pyramidal neurons (Fig. 4) confirmed previous reports of significant age-related reductions in pyramidal cell density, as assessed by counts of neuronal nucleoli within stratum pyramidale of field CAl (nucleoli/100 $\mu \mathrm{m}$, mean \pm SEM; young controls, $4.06 \pm 0.15$; midaged controls, $3.68 \pm 0.19$; aged controls, $3.47 \pm 0.24 ; p$ $<0.001$; cf. Fig. 5). 


\section{Thresholds}
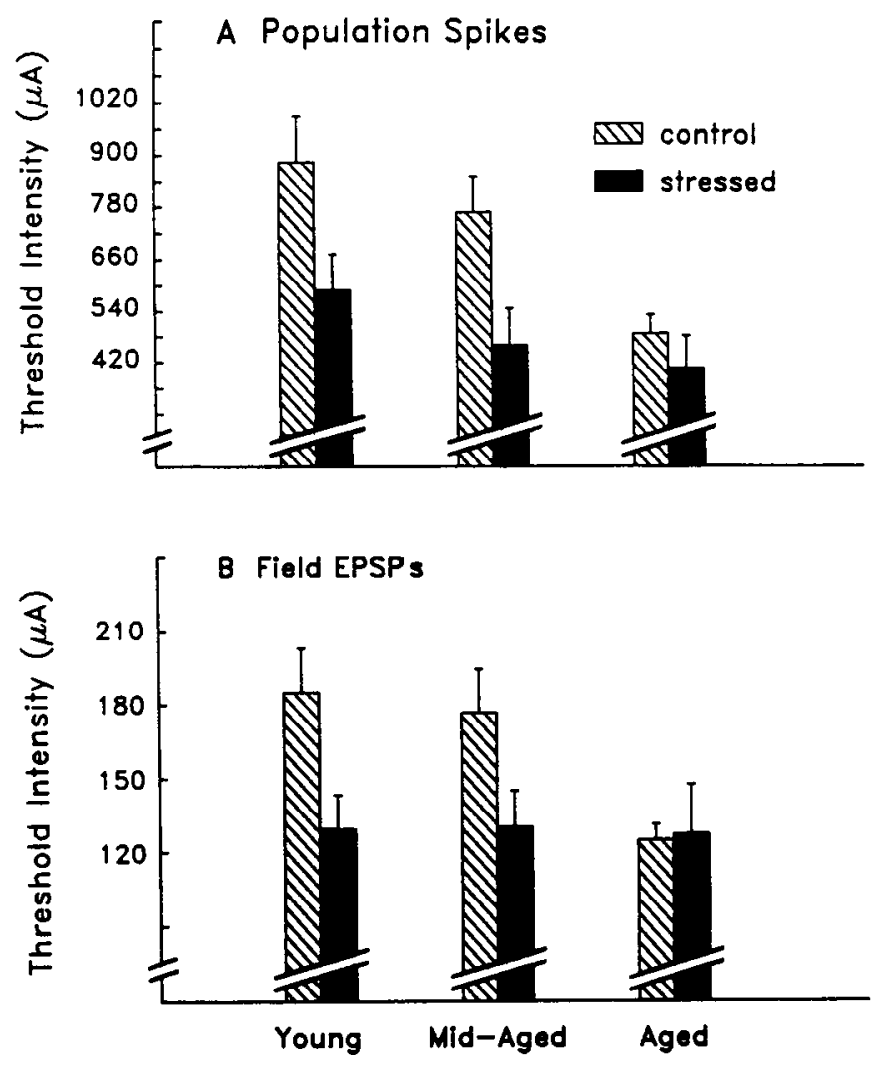

Figure 2. Threshold values $(\mu \mathrm{A}$, mean \pm SEM) for hippocampal potentials from young, midaged, and aged animals (nonstressed vs. stressed). $A$, Population spike thresholds. $B$, Field EPSP thresholds. Thresholds were defined as the stimulus intensity in $\mu \mathrm{A}$ required to produce a 0.5 $\mathrm{mV}$ evoked potential, in response to Schaffer collateral/commissural activation. Main effects of age were seen on both responses. Stress lowered thresholds in young and midaged groups, but not in the aged group.

\section{Effects of stress}

Several effects of chronic stress were also found across these variables. As noted, however, these differed considerably as a function of age group. Chronically stressed animals exhibited reduced population spike thresholds for both the young and midaged groups (stressed vs. nonstressed, $p=0.002$; cf. Fig. $2 A$ ) but not for aged animals. Similar effects were observed for field EPSP thresholds (stressed vs. nonstressed, $p<0.02$; cf. Fig. $2 B$ ). It should be noted that the aged group, for which no effects of stress were seen, already exhibited lower thresholds, and therefore, a "floor" effect might have blocked added effects of the stress paradigm.

FP of the EPSP was also reduced as a function of stress in the youngest group $(F=4.37 ; p<0.05)$, but was not affected in the two older groups (cf. Fig. 3). Again, this result suggests that some form of "floor" effect in the older groups might have blocked further effects of the chronic stress paradigm.

In terms of maximal amplitude of monosynaptically evoked responses, no significant effects of stress were observed on population spike amplitude, though the stress effect was nearly significant in the oldest group $(p=0.07$; Table 1). Because population spike amplitude is thought to reflect directly the number of discharging neurons (Andersen, 1975), it appears possible

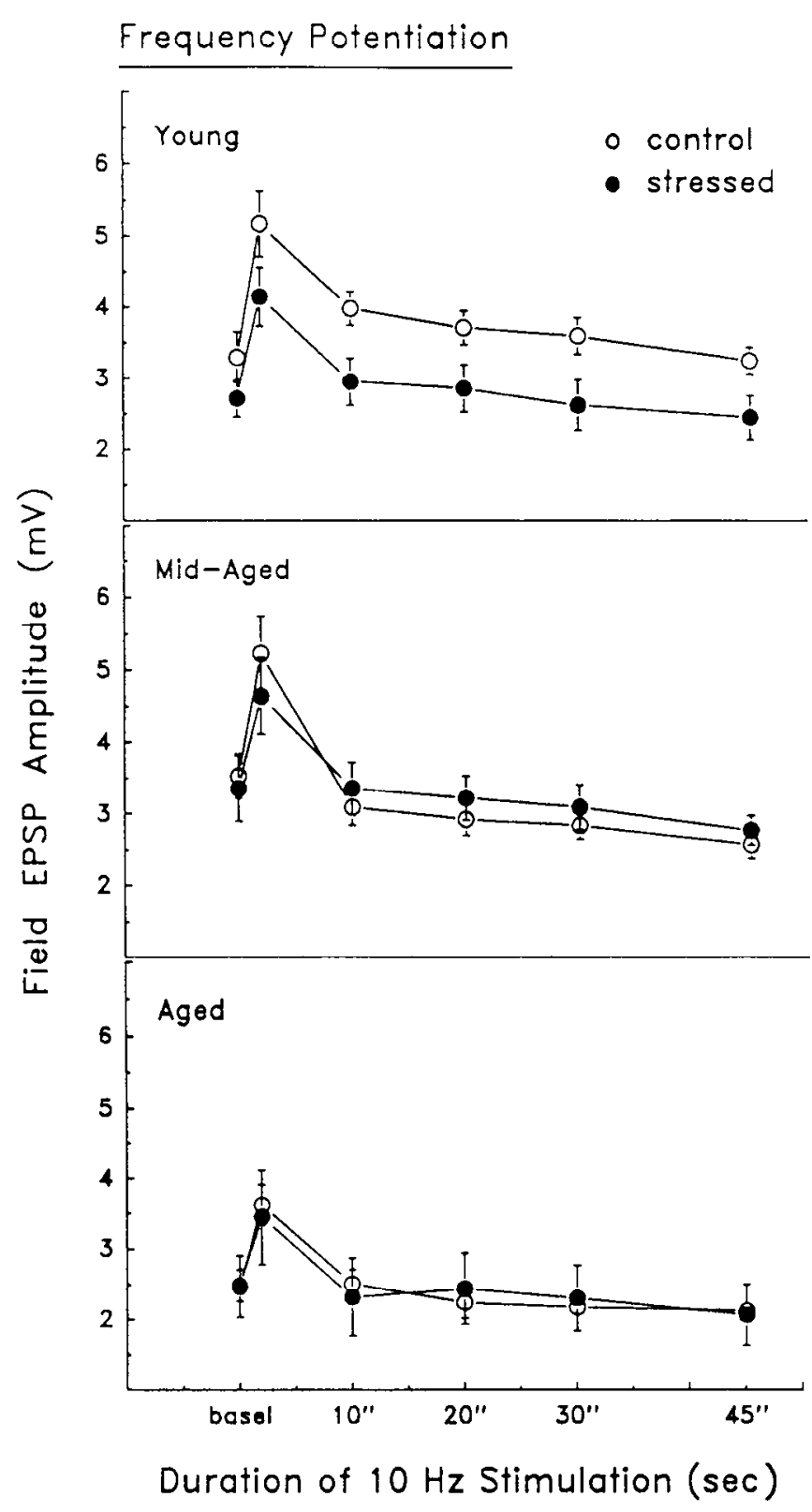

Figure 3. FP of field EPSP amplitudes ( $\mathrm{mV}$, mean \pm SEM) from young, midaged, and aged rats (nonstressed vs. stressed). Time points shown are just prior to (basel) and during $45 \mathrm{sec}$ of $10-\mathrm{Hz}$ Schaffer collateral/ commissural synaptic stimulation. Aging reduced the degree of FP, and stress reduced FP in the young group.

that this tendency is an electrophysiological concomitant of the anatomical effects of stress noted below. (On the other hand, population spike amplitude does not reflect the decrease in neuronal density that occurs simply with aging; cf. Table 1.)

Maximal field EPSPs were not affected by stress for any age group. However, fiber spike amplitude at the lowest stimulus intensity required for maximal field EPSP amplitude tended to be lower in stressed animals of all age groups and was significantly lower $(p<0.01)$ in the midaged group. This suggests that less afferent input may be needed to achieve the same EPSP amplitude and, in conjunction with the threshold data (Fig. 2), indicates that stress may increase excitability by actions at the synapse, rather than by increasing the number of fibers activated by a given stimulus.

The aged stress group showed significantly lower neuronal 

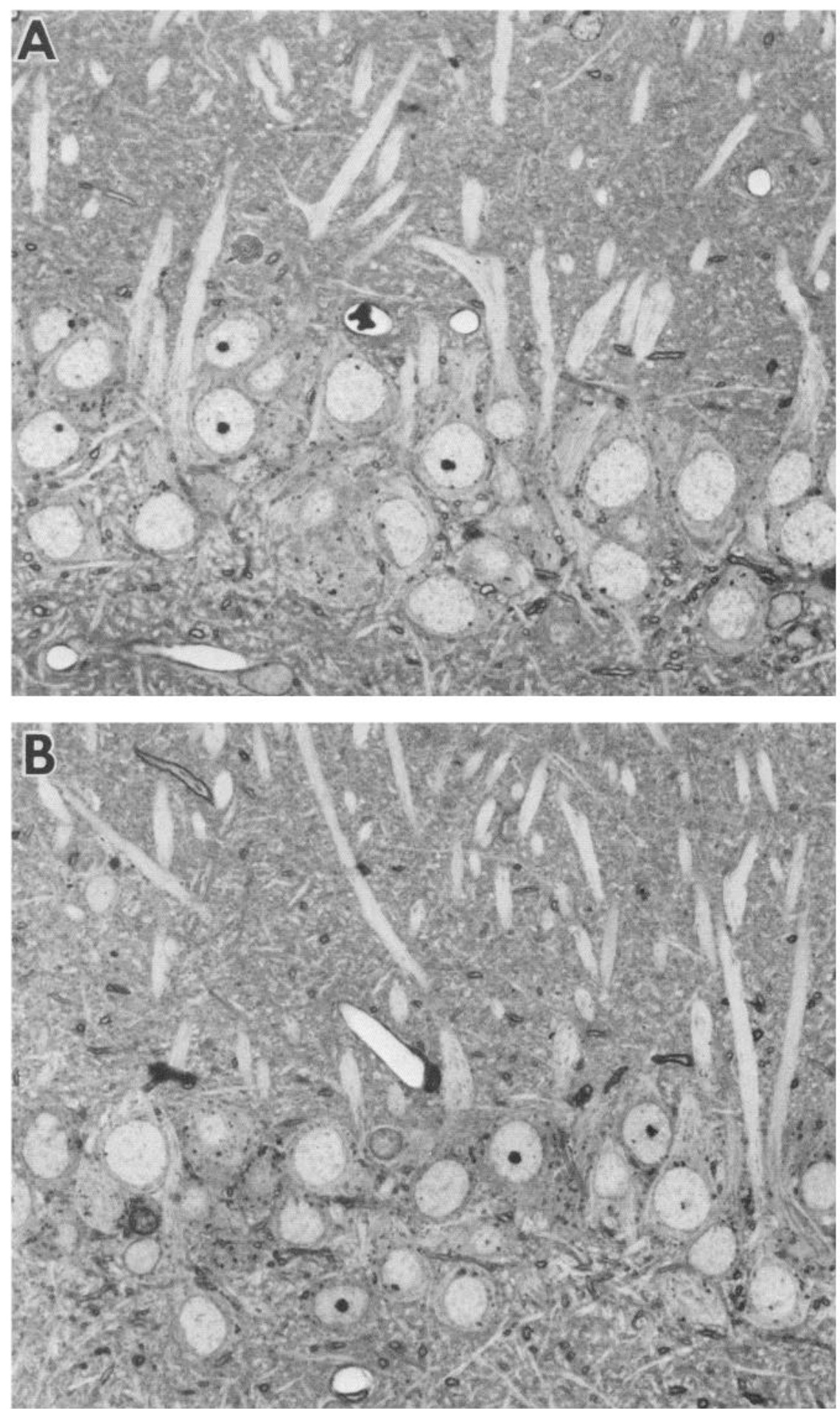

Figure 4. Examples of hippocampal neurons from stratum pyramidale of field $\mathrm{CA} 1$, in toluidine blue-stained semithin sections. $A$, Young control. $B$, Aged control. Pyramidal cell apical dendrites in stratum radiatum are seen in the upper part of each photomicrograph. Magnification, $\times 725$. density than the aged control group ( $p<0.02$; Fig. 5), but no effects of stress on neuronal density were observed in the two younger groups. In terms of the age groups most susceptible to effects of stress, this result for an anatomical marker is essentially the opposite of what was seen for electrophysiological markers.

\section{Discussion}

The biomarkers of brain aging employed in this study yielded reasonably good separation of age groups and were consistent with previous reports of aging effects on these variables. Consequently, the results indicate that 6 months of moderate, neardaily stress (escape training) is able to accelerate functional as well as morphologic markers of hippocampal aging. That is, for thresholds, FP, and neuronal density, one or more of the chronic stress groups exhibited significant differences from its agematched control group, in the direction of the changes seen with aging. In addition to changes in established biomarkers, fiber spike amplitude at EPSP maximum was also reduced in stressed 


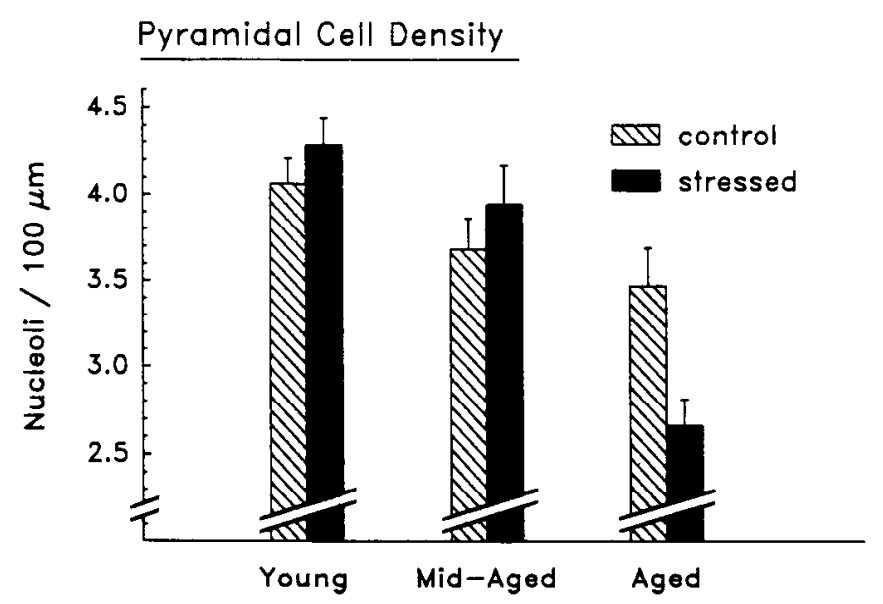

Figure 5. Pyramidal cell density values, expressed as number of nucleoli (mean \pm SEM) per $100 \mu \mathrm{m}$ of stratum pyramidale length, for young, midaged, and aged (nonstressed vs. stressed) rats. Main effects of age were observed, and chronic stress resulted in an increase in cell loss for the aged group.

groups; however, this is likely another manifestation of the reduced threshold effect of stress, because with greater excitability, the maximum EPSP should be attained with a smaller fiber spike.

One of the main results of this study is that the effects of chronic stress on these markers differed markedly across age groups. Moreover, the pattern of stress effects on age groups differed substantially for neurophysiologic and morphologic variables, in that effects of chronic stress on electrophysiologic markers were seen in the youngest groups (young and midaged for threshold, young for FP; cf. Figs. 2, 3), whereas effects of stress on the morphologic index were present only in the oldest group (Fig. 4). A trend to an exception to this pattern, however, was seen in the maximal amplitude of the population spike (Table 1), which may arise from the close corrclation that cxists between neuronal population and spike amplitude.

These patterns raise the possibility that functional markers of brain aging (e.g., threshold, FP) may be susceptible to acceleration by stress-related hormonal/physiological factors relatively early in adult life, but may exhibit a minimal level ("floor") of activity that is independent of extrinsic influences. This minimal level might be reached normally in nonstressed animals by 24 months of age, and therefore chronic stress in this age range would not further exacerbate physiologic decline.

One possible explanation of both the physiologic and morphologic effects could lie in an action of stress on Ca homeostasis within hippocampal neurons. That is, glucocorticoids were found recently to increase voltage-dependent $\mathrm{Ca}$ influx into hippocampal neurons (Joëls and de Kloet, 1989; Kerr et al., 1989) and to do so more effectively in neurons of aged rats (Kerr et al., 1989). Although this effect has as yet been seen only at the soma, glucocorticoids also might well increase $\mathrm{Ca}$ influx at synapses.

Further indications of possible mediation of the effects of stress by $\mathrm{Ca}$-dependent processes arise from evidence that several major electrophysiologic correlates of neural aging appear to depend on altered $\mathrm{Ca}$ homeostasis. That is, aged rat hippocampal neurons are characterized by greater $\mathrm{Ca}$ influx through voltage-sensitive channels at the soma, resulting in larger and longer Ca-dependent afterhyperpolarizations (AHPs; e.g., Land- field and Pitler, 1984; Campbell et al., 1989; Kerr et al., 1989; Pitler and Landfield, 1990); impairment of synaptic FP of aged rat hippocampal neurons is apparently due to excess $\mathrm{Ca}$ influx (cf. Landfield et al., 1986; Applegate and Landfield, 1988); and $\mathrm{Ca}$ clearance from nerve terminals or synaptosomes is also reduced with aging (Michaelis et al., 1984; Smith, 1988a). (There appear to be at least two mechanisms of excess $\mathrm{Ca}$-induced impairment of FP, including Ca-dependent inactivation of presynaptic $\mathrm{Ca}$ currents, and $\mathrm{Ca}$ activation of postsynaptic, and possibly presynaptic, AHPs; cf. Landfield et al., 1986; Applegate and Landfield, 1988.)

With regard to thresholds, Barnes and McNaughton (1980) have speculated that the age-related reduction in thresholds may be a compensatory response to synaptic deafferentation, at least in the dentate gyrus. However, it is not yet clear how, or if, aging or stress effects on Ca homeostasis might alter EPSP thresholds. The Ca-dependent AHP develops too slowly to regulate thresholds, but one possibility is suggested by ultrastructural studies that found a higher proportion of synaptic vesicles adjacent to $\mathrm{Ca}$-dependent release sites at aged synapses (Applegate and Landfield, 1988); obviously, however, other possible explanations exist.

The Ca-dependent AHP is a potent regulator of neuronal excitability (e.g., Alger and Nicoll, 1980; Schwartzkroin and Stafstrom, 1980), and reduced AHPs have been correlated with the acquisition of learned information (Disterhoft et al., 1988). Hippocampal FP has also been correlated with memory/learning ability in aged rats (Landfield et al., 1978; Landfield and Morgan, 1984). Further, it appears possible to reverse at least some the age-related electrophysiologic and behavioral impairments by $\mathrm{Ca}$ antagonists, including magnesium (Landfield and Morgan, 1984; Landfield et al., 1986) and nimodipine, an L-channel Ca antagonist (Deyo et al., 1989; Scriabine et al., 1989). Thus, aging and/or stress-induced alterations in Ca homeostasis could disrupt function of several hippocampal processes known to correlate closely with learning and memory phenomena.

Similarly, biomarkers of brain aging that involve structural change (e.g., neuronal loss) could well be influenced strongly by altered $\mathrm{Ca}$ homeostasis. That is, it is widely recognized that elevated/altered intracellular $\mathrm{Ca}$ can induce degenerative changes in neurons and other excitable cells (Nayler et al., 1979; Schlaepfer and Hasler, 1979; Siesjö, 1981), and the hypothesis that altered $\mathrm{Ca}$ homeostasis is a final common pathway in brain cell loss with aging is gaining considerable experimental support (cf. Khachaturian, 1984, 1989; Gibson and Peterson, 1987; Landfield, 1987b). Thus, it seems highly feasible that the effect of elevated glucocorticoids on brain cell $\mathrm{Ca}$ influx could account for at least some of the effects of chronic stress on eventual morphologic as well as electrophysiologic markers of aging.

In the present study, chronic stress did not accelerate brain cell loss except in the most aged animals. This result contrasts with the study by Sapolsky et al. (1985) in which exogenous CORT administration to young rats accelerated hippocampal neuronal loss. Consequently, the data suggest that chronic levels of CORT higher than those generated by the moderate stress used in this study are necessary to induce cell loss in younger animals, and, as a corollary, that aged rat neurons are more susceptible to the neurodegenerative effects of chronic stress (i.e., are influenced by treatments that do not influence younger animals). Thus, there appears to be an aging-dependent "cofactor" that enhances the toxic impact of stress on brain cells. 
Thus, there appears to be an aging-dependent "cofactor" that enhances the toxic impact of stress on brain cells.

The possibility of a "susceptibility cofactor" in aged brain is consistent with the greater effect of CORT on Ca influx in aged hippocampal neurons (e.g., Kerr et al., 1989), and several potentially relevant aging-related changes in hippocampal CORT receptors have been described recently. These include resistance to downregulation (and higher receptor concentrations) of type II CORT receptors in intact animals (Eldridge et al., 1989; Landfield et al., 1990) and increased affinity of type II receptors for glucocorticoid ligands (Landfield and Eldridge, 1989). Conceivably, the capacity for receptor downregulation might confer a "protective" effect of some kind in young animals. If this protective capacity declined with aging, the neurodegenerative impact of CORT might well be increased. Alternatively, plasma CORT could remain elevated longer in aging rats. That is, plasma CORT is increased in aging rats (Landfield et al., 1978b; DeKosky et al., 1984), apparently because of slower return to baseline levels following stress (Sapolsky et al., 1986). Moreover, plasma CORT elevation adapts more slowly in aged animals in a similar chronic stress paradigm (Odio and Brodish, 1989). However, it is still far from certain that aging changes in corticosteroids or their receptors are cofactors responsible for the increased brain susceptibility. There are numerous alternative possibilities, including age-related changes in other mechanisms of Ca homeostasis.

Further, these studies of course do not demonstrate conclusively that physiologically elevated CORT was specifically responsible for the apparent acceleration of brain aging-like markers in any age group. Clearly, the possibility cannot be ruled out that other physiological effects of stress (e.g., catecholamine release, blood pressure changes, etc.) contributed to these brain changes. For example, stress-induced effects on neuroendocrine responses other than CORT receptor downregulation, such as inhibition of thyroid-stimulating hormone, are also blunted with aging (Simpkins et al., 1978). Consequently, it will be important in future studies to determine whether chronic stress alters markers of brain aging in adrenalectomized rats.

Nevertheless, these data provide the first clear evidence, from a defined and regulated moderate chronic stress paradigm, that a treatment that chronically elevates endogenous CORT activity (Odio and Brodish, 1989) at hippocampal CORT receptors (Eldridge et al., 1989) can also accelerate and/or exacerbate the development of well-characterized biomarkers of hippocampal aging in a mammalian species. Functional electrophysiologic as well as morphologic indicants of hippocampal aging can be increased by these paradigms. Further, the susceptibility of functional and anatomical markers to stress differs substantially as a function of age, suggesting, on the one hand, a possible "floor" effect for electrophysiologic markers and, on the other, the operation of an aging-related cofactor in the acceleration of morphologic markers.

In addition, if these effects in a mammalian model are relevant to human conditions, the results raise the possibilities that (1) chronic stress in young and midaged humans could alter neurophysiologic mechanisms important for normal memory and other cognitive functions, and (2) aged individuals could be more sensitive than young to neurodegenerative (and perhaps other) actions of chronic stress. Moreover, the possibility exists that greatly accelerated neuronal degeneration, such as occurs in Alzheimer's disease, might develop in a subpopulation of aging individuals who are particularly susceptible to stress.

\section{References}

Alger BE, Nicoll RA (1980) Epileptiform burst afterhyperpolarization: calcium-dependent potassium potential in hippocampal CA 1 pyramidal cells. Science 210:1122-1144.

Andersen P (1975) Organization of hippocampal neurons and their interconnections. In: The hippocampus (Isaacson RL, Pribram KH, eds), pp 155-175. New York: Plenum.

Andersen P, Lomo T (1967) Control of hippocampal output by afferent volley frequency. Prog Brain Res 27:400-412.

Applegate MD, Landfield PW (1988) Synaptic vesicle redistribution during hippocampal frequency potentiation and depression in young and aged rats. J Neurosci 8:1096-1111.

Baker GT, Sprott RL (1988) Biomarkers of aging. Exp Gerontol 23: 223-240.

Barnes CA (1979) Memory deficits associated with senescence: a behavioral and neurophysiological study in the rat. J Comp Physiol Psychol 93:74-104.

Barnes CA, McNaughton BL (1980) Physiological compensation for loss of afferent synapses in rat hippocampal granule cells during senescence. J Physiol (Lond) 309:473-485.

Bickford-Wimer PC, Miller JA, Freedman R, Rose GM (1988) Agerelated reduction in responses of rat hippocampal neurons to locally applied monoamines. Neurobiol Aging 9:173-179.

Campbell LW, Hao S-Y, Landfield PW (1989) Aging-related increases in L-like calcium currents in rat hippocampal slices. Soc Neurosci Abstr 15:206.

Coleman PD, Flood DG (1987) Neuron numbers and dendritic extent in normal aging and Alzheimer's disease. Neurobiol Aging 8:521545 .

DeKosky ST, Scheff SW, Cotman CW (1984) Elevated corticosterone levels: possible cause of reduced axon sprouting in aged animals. Neuroendocrinology 38:33-38.

Deyo RA, Straube KT, Disterhoft JF (1989) Nimodipine facilitates associative learning in aging rabbits. Science 243:809-811.

Disterhoft JF, Golden DT, Read HL, Coulter DA, Alkon DL (1988) AHP reductions in rabbit hippocampal neurons during conditioning correlate with acquisition of the learned response. Brain Res 462:118125.

Eldridge JC, Landfield PW (1990) Cannabinoid interactions with glucocorticoid receptors in rat hippocampus. Brain Res 534:135-141.

Eldridge JC, Brodish A, Kute TE, Landfield PW (1989) Apparent agerelated resistance of type II hippocampal corticosteroid receptors to down-regulation during chronic escape training. J Neurosci 9:32373242 .

Foy MR, Stanton ME, Levine S, Thompson RF (1987) Behavioral stress impairs long-term potentiation in rodent hippocampus. Behav Neural Biol 48:138-149.

Gibson GE, Peterson C (1987) Calcium and the aging nervous system. Neurobiol Aging 8:329-344.

Humphrey DR (1968) Re-analysis of the antidromic cortical response. II. On the contribution of cell discharge and PSPs to the evoked potentials. EEG Clin Neurophysiol 25:421-442.

Ingram DK (1988) Key questions in developing biomarkers of aging. Exp Gerontol 23:429-434.

Joëls M, de Kloet ER (1989) Effects of glucocorticoids and norepinephrine in the hippocampus. Science 245:1502-1505.

Kelly SS, Robbins N (1987) Statistics of neuromuscular transmitter release in young and old mouse muscle. J Physiol (Lond) 385:507516.

Kerr DS, Campbell LW, Hao S-Y, Landfield PW (1989) Corticosteroid modulation of hippocampal potentials: increased effect with aging. Science 245:1505-1509.

Khachaturian ZS (1984) Towards theories of brain aging. In: Handbook of studies on psychiatry and old age (Kay D, Burrows GD, eds), pp 7-30. Amsterdam: Elsevier.

Khachaturian ZS (1989) The role of calcium regulation in brain aging: reexamination of a hypothesis. Aging 1:17-34.

Konigsmark BW (1970) Methods for counting of neurons. In: Contemporary research methods in neuroanatomy (Nauta W, Ebbesson SO, eds), pp 315-340. Berlin: Springer.

Landfield PW (1978) An endocrine hypothesis of brain aging and studies on brain-endocrine correlations and monosynaptic neurophysiology during aging. In: Parkinson's disease 11 (Finch CE, Potter DE, Kenny AD, eds), pp 179-199. New York: Plenum. 
Landfield PW (1987a) Modulation of brain aging correlates by longterm alterations of adrenal steroids and neurally active peptides. Prog Brain Res 72:279-300.

Landfield PW (1987b) 'Increased calcium current' hypothesis of brain aging. Neurobiol Aging 8:346-347.

Landfield PW (1988) Commentary on biomarkers of aging in the nervous system. Exp Gerontol 23:413-416.

Landfield PW, Deadwyler SA, eds (1988) Long-term potentiation: from biophysics to behavior. New York: Liss.

Landfield PW, Eldridge JC (1989) Increased affinity of type II corticosteroid binding in aged rat hippocampus. Exp Neurol 106:110-113.

Landfield PW, Morgan G (1984) Chronically clcvating plasma $\mathbf{M g}^{2+}$ improves hippocampal frequency potentiation and reversal learning in aged and young rats. Brain Res 322:167-171.

Landfield PW, Pitler TA (1984) Prolonged $\mathrm{Ca}^{2+}$-dependent afterhyperpolarizations in hippocampal neurons of aged rats. Science 226: 1089-1092.

Landfield PW, McGaugh JL, Lynch GS (1978a) Impaired synaptic potentiation processes in the hippocampus of aged, memory-deficient rats. Brain Res 150:85-101.

Landfield PW, Waymire JL, Lynch GS (1978b) Hippocampal aging and adrenocorticoids: quantitative correlations. Science 202:10981102.

Landfield PW, Baskin RK, Pitler TA (1981a) Brain aging correlates: retardation by hormonal-pharmacological treatments. Science 214: 581-584.

Landfield PW, Braun LD, Pitler TA, Lindsey JD, Lynch G (1981b) Hippocampal aging in rats: a morphometric study of multiple variables in semithin sections. Neurobiol Aging 2:265-275.

Landfield PW, Pitler TA, Applegate MD (1986) The effects of high $\mathrm{Mg}^{2+}-$ to- $\mathrm{Ca}^{2+}$ ratios on frequency potentiation in hippocampal slices of young and aged rats. J Neurophysiol 56:797-811.

Landfield PW, Cadwallader LB, Vinsant S (1988) Quantitative changes in hippocampal structure following long-term exposure to delta-9tetrahydrocannabinol: possible mediation by glucocorticoid systems. Brain Res 443:47-62.

Landfield PW, Booze RM, Vinsant S, Cadwallader LB, Eldridge JC (1990) Glucocorticoid receptor immunostaining is increased in aged hippocampus. Soc Neurosci Abstr 16:31.

Martin AR (1977) Presynaptic mechanisms. In: Handbook of physiology, I, The nervous system (Brookhart JM, Mountcastle VB, eds), pp 329-355. Bethesda, MD: American Physiological Society.

McEwen BS, de Kloet ER, Wallach G (1986) Adrenal steroid receptors and actions in the nervous system. Physiol Rev 66:1121-1188.

Meaney MJ, Aitken DH, Bhatnagar S, Van Berkel C, Sapolsky RM (1988) Postnatal handling attenuates neuroendocrine, anatomical, and cognitive impairments related to the aged hippocampus. Science 238:766-768.

Michaelis ML, Johe K, Kitos TE (1984) Age-dependent alterations in synaptic membrane systems for $\mathrm{Ca}^{2+}$ regulation. Mech Ageing Dev 25:215-225.

Nayler WG, Poole-Wilson PA, Williams A (1979) Hypoxia and calcium. J Mol Cell Cardiol 11:683-706.

Odio M, Brodish A (1989) Age-related adaptation of pituitary-adrenocortical responses to stress. Neuroendocrinology 49:382-388.
O'Steen WK, Brodish A (1985) Neuronal damage in the rat retina after chronic stress. Brain Res 344:231-239.

O'Steen WK, Sweatt AJ, Eldridge JC, Brodish A (1987) Gender and chronic stress effects on the neural retina of young and mid-aged Fischer-344 rats. Neurobiol Aging 8:449-455.

Pitler TA, Landfield PW (1987) Postsynaptic membrane shifts during frequency potentiation of the hippocampal EPSP. J Neurophysiol 58: 866-882.

Pitler TA, Landfield PW (1990) Aging-related prolongation of calcium spike duration in rat hippocampal slice neurons. Brain Res 508:1-6.

Rose GM, Gerhardt GA, Conboy GL, Hoffer BJ (1986) Age-related alterations in monoamine relcasc from rat striatum: an in vivo electrochemical study. Neurobiol Aging 7:77-82.

Rosenheimer JL (1985) Effects of chronic stress and exercise on agerelated changes in end-plate architecture. J Neurophysiol 53:15821589.

Sapolsky RM, Krey LC, McEwen BS (1985) Prolonged glucocorticoid exposure reduces hippocampal neuron number: implications for aging. J Neurosci 5:1222-1227.

Sapolsky RM, Krey LC, McEwen BS (1986) The neuroendocrinology of stress and aging: the glucocorticoid cascade hypothesis. Endocr Rev 7:284-301.

Schlaepfer WW, Hasler MB (1979) Characterization of the calciuminduced disruption of neurofilaments in rat peripheral nerve. Brain Res 168:299-309.

Schwartzkroin PA, Stafstrom CE (1980) Effects of EGTA on the calcium-activated afterhyperpolarization in hippocampal CA3 pyramidal cells. Science 210:1125-1126.

Scriabine A, Schuurman T, Traber J (1989) Pharmacological basis for the use of nimodipine in central nervous system disorders. FASEB J 3:1799-1806.

Shors TJ, Seib TB, Levine S, Thompson RF (1989) Inescapable versus escapable shock modulates long-term potentiation in the rat hippocampus. Science 244:224-226.

Siesjö B (1981) Cell damage in the brain: a speculative synthesis. J Cereb Blood Flow Metab 1:155-185.

Simpkins JW, Hodson A, Meites J (1978) Differential effects of stress on release of thyroid-stimulating hormone in young and old male rats. Proc Soc Exp Biol Med 157:144-147.

Simpson CW, DiCara LV, Wolf G (1974) Glucocorticoid anorexia in rats. Pharmacol Biochem Behav 2:19-25.

Smith DO (1988a) Muscle-specific decrease in presynaptic calcium dependence and clearance during neuromuscular transmission in aged rats. J Neurophysiol 59:1069-1082.

Smith DO (1988b) Cellular and molecular correlates of aging in the nervous system. Exp Gerontol 23:399-412.

Stevenson JA, Franklin C (1970) Effects of ACTH and corticosteroids in the regulation of food and water intake. Prog Brain Res 32:141151.

Swanson LW, Wyss JM, Cowan WM (1978) An autoradiographic study of the organization of intrahippocampal association pathways in the rat. J Comp Neurol 151:681-716.

Uno H, Tarara R, Else JG, Suleman MA, Sapolsky RM (1989) Hippocampal damage associated with prolonged and fatal stress in primates. J Neurosci 9:1705-1711. 